\title{
MODELLING THE INFLUENCE OF THE STACKING ORDER ON DAMAGE IN LAMINATED COMPOSITES
}

\author{
M. Nicol ${ }^{1,2 *}$, F. Laurin ${ }^{1}$, M. Hirsekorn ${ }^{1}$, J.-F. Maire ${ }^{1}$, W. Albouy ${ }^{2}$, S. Treutenaere ${ }^{2}$ \\ ${ }^{1}$ ONERA, DMAS, Université Paris-Saclay F-92320 Châtillon, France \\ ${ }^{2}$ Safran Composites, a technology platform of Safran Tech, 33 avenue de la gare, Itteville, France \\ *matthieu.nicol@safrangroup.com
}

Composite materials, especially unidirectional carbon fiber reinforced polymers, are massively used in primary aircraft structures as a lightweight alternative to metal alloys. In industrial applications, a composite laminate layup must comply with numerous design guidelines [1] which restrict the possible stacking sequences at the cost of possibly better layups. Thus, a current challenge is the development of damage models that take into account the influence of the stacking sequence on the mechanical performance of the composite. Currently, models at the ply scale are the most suitable for an industrial use due to their good predictive capabilities at a relatively low computational cost. Yet, they are not able to predict the damage coupling between adjacent plies and the influence of the laminate stacking order on the tensile strength $[2,3]$. To understand the underlying mechanisms, a discrete damage model is proposed: an automatic crack insertion method is built to obtain complete freedom on the location and orientation of the cracks inserted in a finite element mesh (Figure 1). A method based on finite fracture mechanics, is used to compare damaged configurations for different stacking orders and conclude on the more energetically favorable one. The approach is first validated on well known results (e.g. ply thickness effect on damage). It is then used to study the damage coupling between plies and analyze the effect of the stacking order on laminate damage and failure.
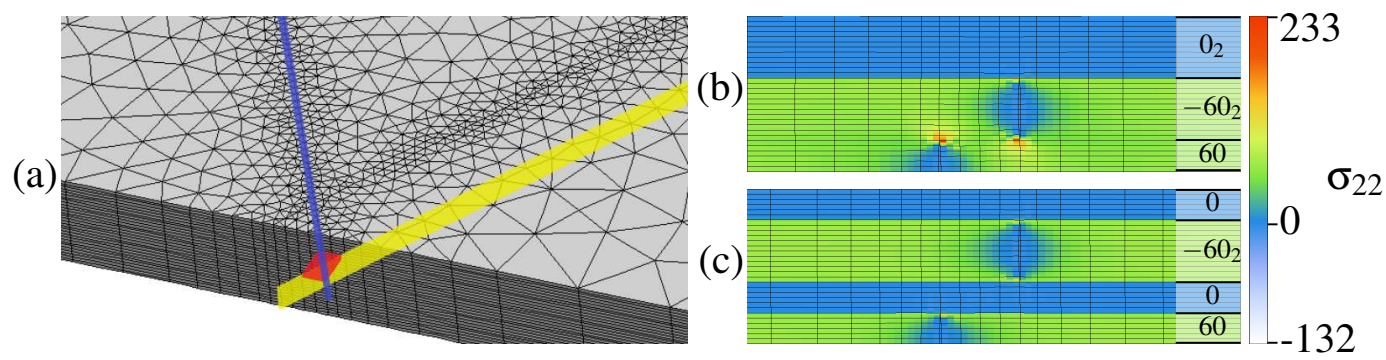

Figure 1: Discrete crack insertion in order to compare two laminates: (a) mesh (transparent: inserted cracks); resulting $\sigma_{22}$ field for (b) laminate $\left[0_{2} /-60_{2} / 60\right]_{s}$ and (c) laminate $\left[0 /-60_{2} / 0 / 60\right]_{s}$.

\section{References}

[1] Composite Materials Handbook - Volume 3: Polymer matrix composites, materials usage, design and analysis. Military Handbook MIL-HDBK-17-3F, U.S. Department of Defense, 2002.

[2] T. Yokozeki, T. Aoki, and T. Ishikawa. Transverse cracking in CFRP laminates with angled plies. In Collection of Technical Papers - AIAA/ASME/ASCE/AHS/ASC Structures, Structural Dynamics and Materials Conference, volume 1, 2002.

[3] C. Huchette. Analyse multiéchelle des interactions entre fissurations intralaminaire et interlaminaire dans les matériaux composites stratifiés. Doctorate thesis, Université Paris VI, 2005. 